\title{
Determining Optimum Design Parameters of Foldable Product Using Response Surface Methodology and Genetic Algorithm
}

\author{
Shahriar Tanvir Alam ${ }^{(0)}$, Mohd Albab Amin \\ Department of Industrial and Production Engineering, Military Institute of Science of Technology (MIST), Dhaka, Bangladesh \\ Email: tanvir.shahriar.tro@gmail.com
}

How to cite this paper: Alam, S.T. and Amin, M.A. (2020) Determining Optimum Design Parameters of Foldable Product Using Response Surface Methodology and Genetic Algorithm. Engineering, 12, 839-850. https://doi.org/10.4236/eng.2020.1211059

Received: October 26, 2020

Accepted: November 27, 2020

Published: November 30, 2020

Copyright (c) 2020 by author(s) and Scientific Research Publishing Inc. This work is licensed under the Creative Commons Attribution International License (CC BY 4.0).

http://creativecommons.org/licenses/by/4.0/

\begin{abstract}
It is desired to optimize design parameters in any product development for achieving the appropriate efficiency level in any manufacturing industry. To select the best materials used, reduce cost, and increase a product's sustainability, an analysis of all design parameters must be conducted. Suitable design parameters and their optimum ranges provide the feasibility in developing a specific product. Response Surface Methodology (RSM) provides the opportunity of checking the parameters after considering optimization strategies, which results in improving the production process. In this study, the research aims to construct a 3D model and a mathematical equation on a foldable product to optimize the design parameters. A 2-level 3 factors small Central Composite Design (CCD) method is used for planning experimental trials, and the primary objective is to determine the optimal value for three design parameters, which are fold angle, length of the cycle, and height between seat and paddle in terms of the response which is "time required to fold the product". This paper directs attention towards response optimization to achieve minimum "time required to fold the product" using the desirability criteria of Response Surface Methodology (RSM) and the optimization approach of the Genetic Algorithm (GA). The optimum value of "time required to fold the product" is found to be 2.415 seconds with a combination of design parameters such as "fold angle" of $180^{\circ}$, "length of the cycle" of $74.112 \mathrm{~cm}$, and "height between seat and paddle" of $0.613 \mathrm{~m}$ using Response Surface Methodology (RSM). The Genetic Algorithm (GA) predicts the "time required to fold the product" is 2.39 seconds and design parameters of "fold angle" of $179.559^{\circ}$, "length of the cycle" of $74.1 \mathrm{~cm}$, and "height between seat and paddle" of $0.59 \mathrm{~m}$. This similar sort of analysis can be implemented in different manufacturing industries for developing a specific product.
\end{abstract}


Keywords

RSM, GA, Desirability, Foldable Product, CCD

\section{Introduction}

The elimination of time-consuming functionality provides additional value along with providing the primary purpose of any product. The design phase in product development is to provide all items that have been considered in the measure and analysis phases [1]. In the design phase of any new product, the design parameters must be optimized to function appropriately within the least time for selecting low time-consuming functionality [2]. People working in product development have experienced significant changes in the design phase of a product development process. So, the design must be conducted and reviewed extensively for satisfying the customer during the design phase of a product development process.

This research study considers a foldable cycle with a foldability function consisting of the front fork and rear gear assembly with four small wheels. The front fork and rear gear assembly of the cycle are joined by a knuckle joint to fold the cycle. The foldable cycle is designed to fold the product into a compact form, facilitating transport and storage [3]. The cycle can be more easily carried into different places with the back four small wheels attached with the back seat of the cycle and more easily stored in a compact living place in folded condition. The two main wheels of the cycle remain side by side in the folded condition of the cycle. For making the folding operation more time-efficient, the time needed to fold the product requires to be minimized. Response Surface Methodology (RSM) can be conducted at the design phase of product development to compensate for this fact. RSM can be used for optimizing the design parameters, which affect the response named "time required to fold the product". RSM consists of mathematical and statistical techniques based on empirical models' fit to the experimental data obtained with experimental design [4] [5]. "Response Surface Methodology (RSM) establishes the relationships between several explanatory variables and one or more responses or outcomes" [6] [7]. The number of experiments required is affected by the Design of Experiment (DOE); hence it is essential to adopt an appropriate experimental design. Several experimental designs are available, including central composite design (CCD), Box-Behnken, Plackett Burman, full factorial. This 2-level small CCD is the most appropriate method for this study, which requires a sufficient number of experimental runs to provide a minimum error. The models developed were based on only a few experimental results [8] [9]. Regression is performed to an approximate empirical variable (response) based on a functional relationship between the estimated response function and one or more regressors or input variables [10]. RSM involves the following steps: 1) The postulation of the mathematical model [11].2) 
Experimental design. 3) Estimation of test region (Coding) for independent variables. 4) Estimation of parameters in the postulated model. 5) Analysis of results by a) Checking the adequacy of the postulated model and the test for significance of individual variables by analysis of variance (ANOVA) [11]. b) The precision of prediction, i.e., the estimation of confidence intervals [11] [12]. As this study intended to investigate all factors' effects and interactions, the small factorial design of experiments is used to find the optimum range of the design parameters.

This paper is organized as: Section 2 describes the methodology and design parameters. Section 3 shows the 3D model and design of experiments analysis, and Section 4 interprets the research results. Section 5 presents the conclusion and recommendations.

\section{Methodology}

A response is obtained at different level settings to which the design parameters are set for experimental work. The optimum value of a response depends on the setting range of all design parameters. Any input to the process is a factor which can be set to the desired value or can be selected from the available options. On the other hand, any output from a process is a response [13]. The general equation for the experimental factorial design is as follows:

$$
Y=\beta_{0}+\beta_{1} X_{1}+\beta_{2} X_{2}+\beta_{11} X_{1}^{2}+\beta_{22} X_{2}^{2}+\beta_{12} X_{1} X_{2}+\varepsilon
$$

where $Y$ is the level of the measured response, $\beta_{0}$ is the intercept, $\beta_{1}, \beta_{12}$ are the regression coefficients. $X_{1}, X_{2}$ and $X_{3}$ stand for the main effects. $X_{1} X_{2}, X_{2} X_{3}$ and $X_{3} X_{1}$ are the interaction between the main effects. $X_{1}^{2}$, $X_{2}^{2}$ and $X_{3}^{2}$ are the quadratic terms of the independent variables used to simulate the designed sample space [14]. In this article, the response is the time required to fold the product. The response depends on the fold angle, length of the cycle, and the height between seat and paddle. The fold angle depends on the folding mechanism of the cycle. The folded $\left(15^{\circ}\right)$ and unfolded $\left(180^{\circ}\right)$ conditions are illustrated in Figure 1.

Small factorials designed experiment consists of all possible combinations of levels for design parameters [15]. CCD is an experimental design used in RSM

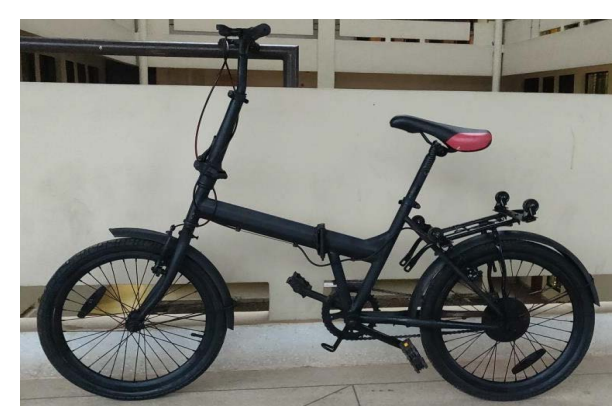

(a)

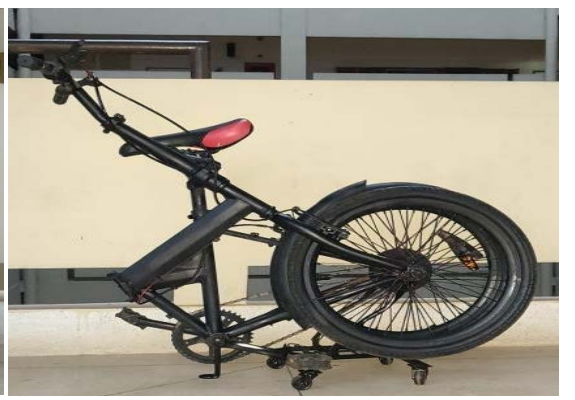

(b)

Figure 1. (a) Unfolded $\left(180^{\circ}\right)$ condition and (b) Folded $\left(15^{\circ}\right)$ condition of the product. 
for developing a second-order model for the response [16]. Central Composite Design (CCD) with 3 factors was applied to investigate the foldable cycle's response. CCD consists of 3 parts, such as factorial points, center points, axial points. A total of 15 experimental runs (small CCD) are sufficient to calculate the second-order polynomial regression model's coefficient for three variables. In this study, 15 experimental runs, including 5 similar experimental runs for the center points and 2 experimental runs for checking the optimum value for the response outside of the given range of input design parameters. The process of the foldability of the product is illustrated in Figure 2. The list of the design parameters, along with their levels, is represented in Table 1.

\section{Design Analysis}

\subsection{Experimental Layout}

The times are measured for different experimental runs of design parameters and recorded as a response for this study. The experimental layout is illustrated in Table 2.

\subsection{Pareto Plots}

The main effect of plots or Pareto plots is a plot of the mean response values at each level of design parameters. One can use this plot to compare the relative strength of the effects of various design parameters [17]. In this study, the Pareto plot is used to determine which design parameters significantly affect the response. Pareto plots for the response of the product are presented in Figure 3.

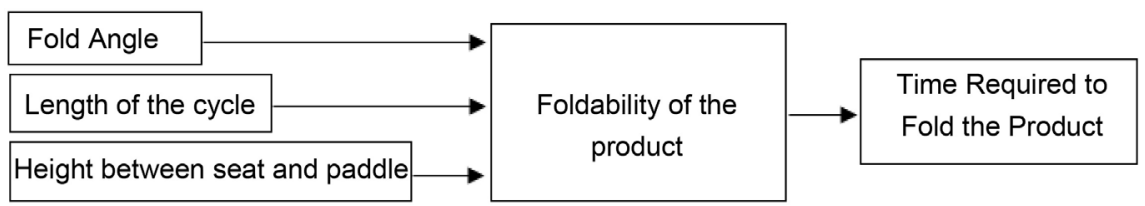

Figure 2. The schematic diagram for the foldability of the product.

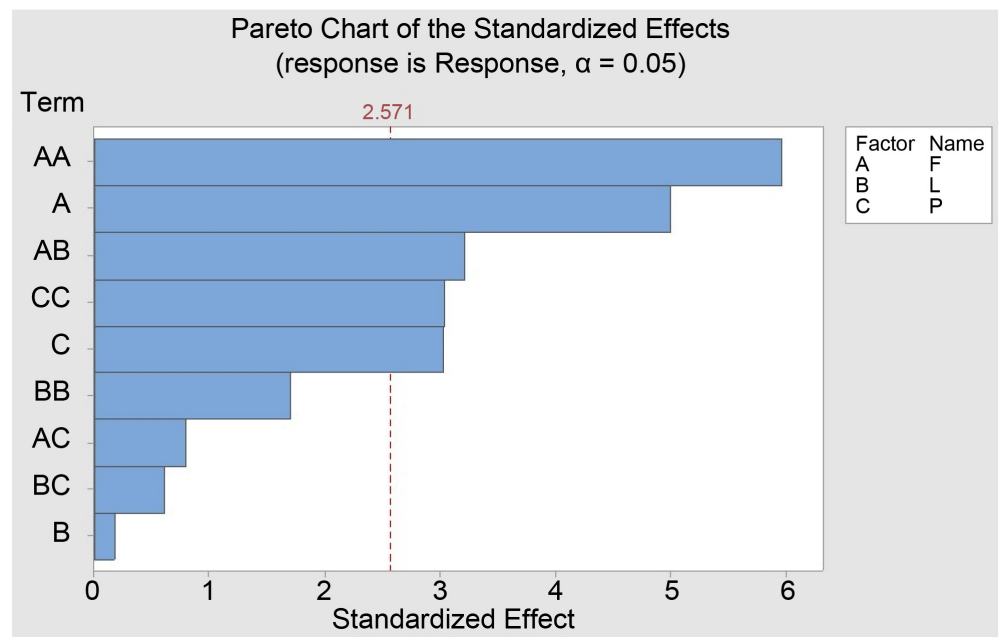

Figure 3. Pareto plot for response. 
Table 1. Design parameters with their levels and labels.

\begin{tabular}{cccc}
\hline Factors & Labels & Low Level & High Level \\
\hline Fold Angle & $\mathrm{F}($ degree $)$ & $15^{\circ}$ & $180^{\circ}$ \\
Length of the cycle & $\mathrm{L}(\mathrm{cm})$ & 50 & 110 \\
Height between seat and paddle & $\mathrm{P}(\mathrm{m})$ & 0.5 & 0.8 \\
\hline
\end{tabular}

Table 2. Experimental layout.

\begin{tabular}{ccccc}
\hline Run & $\begin{array}{c}\text { Factor 1: } \\
\text { F (Degree) }\end{array}$ & $\begin{array}{c}\text { Factor 2: } \\
\text { L (cm) }\end{array}$ & $\begin{array}{c}\text { Factor 3: } \\
\text { P (m) }\end{array}$ & $\begin{array}{c}\text { Response } \\
\text { (second) }\end{array}$ \\
\hline 1 & 97.5 & 80 & 0.862132 & 5.88 \\
2 & 15 & 50 & 0.5 & 11.02 \\
3 & 97.5 & 80 & 0.65 & 5.6 \\
4 & 97.5 & 80 & 0.437868 & 5.198 \\
5 & 97.5 & 122.426 & 0.65 & 5.68 \\
6 & 97.5 & 80 & 0.65 & 5.29 \\
7 & 180 & 50 & 0.8 & 3.29 \\
8 & 97.5 & 37.5736 & 0.65 & 5.79 \\
9 & 15 & 110 & 0.8 & 10.98 \\
10 & 214.173 & 80 & 0.65 & 1.38 \\
11 & 12.1726 & 80 & 0.65 & 11.56 \\
12 & 97.5 & 80 & 0.65 & 5.559 \\
13 & 97.5 & 80 & 0.65 & 5.58 \\
14 & 180 & 110 & 0.5 & 3.33 \\
15 & 97.5 & 80 & 0.65 & 5.12 \\
\hline
\end{tabular}

It can be interpreted that fold angle $(F)$ and length between seat and paddle $(P)$ significantly affect the product's foldability. Other factors, including the interaction between fold angle $(F)$ and the length of the cycle $(L)$, show a noticeable impact on the response.

According to the fit and summery tests, the quadratic model was suggested. The fitted response model for foldability of the product was found to be as:

$$
\begin{aligned}
\text { Response }= & 21.95483-0.072337 F-0.120214 L-20.55898 P \\
& +0.000106 F * L-0.003143 F * P+0.054628 L * P \\
& +0.000114 F^{2}+0.000457 L^{2}+13.92510 P^{2}
\end{aligned}
$$

\subsection{Effect of Design Parameters on the Response}

From the experimental results, it is found that the length of the cycle tends to have minimal effect on the response for a specified range of design parameters. The interaction between $(P)$ along with fold angle $(F)$ and length of the cycle $(L)$ also offers less significant effects over response. The response is found to increase with increasing value of fold angle.

Figure 4 shows the effect of fold angle $(F)$ versus length of the cycle $(L)$ for a 
Factor Coding: Actual

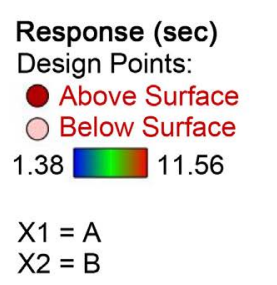

Actual Factor $\mathrm{C}=0.65$

\section{[ᄌ}

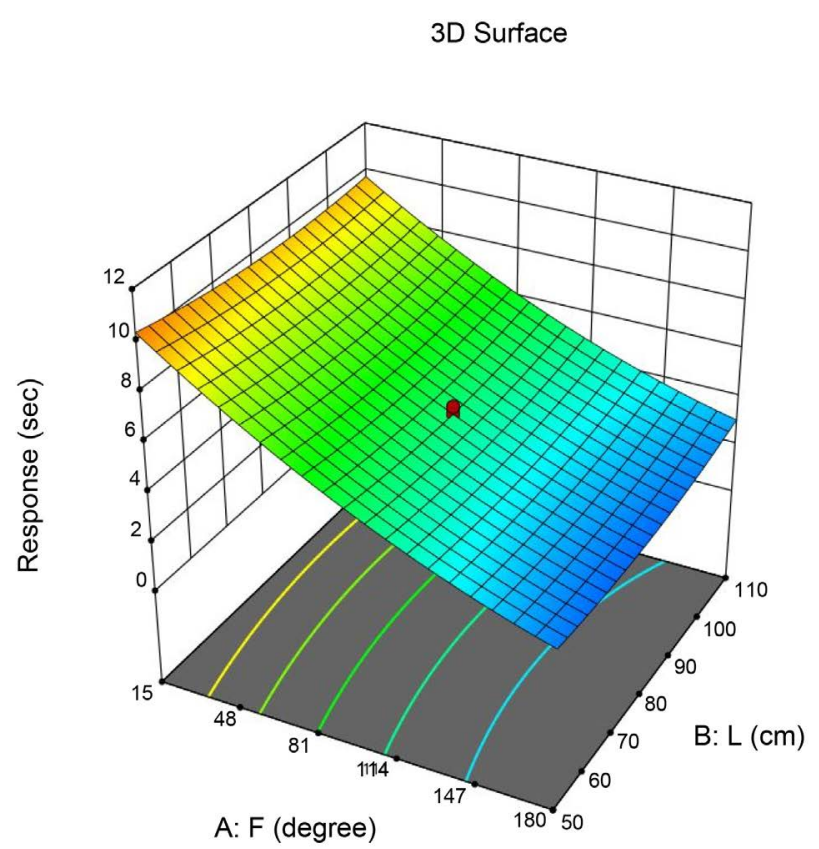

Figure 4. Effect of fold angle (F) vs. length of the cycle (L). (Response as a function of fold angle (F) and length of the cycle (L) for " 0.65 " level value of the height between seat and paddle $(\mathrm{P})$ during the experimental run).

constant height between seat and paddle $(P)$ of $0.65 \mathrm{~m}$. The surface plot has been developed based on the regression model developed using the experimental data. It is understood from the surface plot that the increase in fold angle $(F)$ at the lower height between seat and paddle $(P)$ increases the possibility of finding an acceptable response. Whereas at any length of the cycle $(L)$ and lower height between seat and paddle $(P)$ (less than $0.65 \mathrm{~m}$ ), an acceptable response can be observed. So, for the most acceptable response, the fold angle $(F)$ should be higher (closer to $180^{\circ}$ ) at a lower height between seat and paddle (less than 0.65 $\mathrm{m})$.

\subsection{Optimization by Coupling RSM with GA}

The objective of the optimization is to achieve a lower response in experimental runs. This can be achieved efficiently by adjusting design parameters with the help of an appropriate numerical optimization method. For this, minimization of response must be formulated in the standard mathematical format as below:

Find: $F$ (fold angle), $L$ (length of the cycle), $P$ (height between seat and paddle) Minimum: Time required to fold the product $(F, L, P)$

Within ranges: $\left(F_{\min } \leq F \leq F_{\max }\right),\left(L_{\min } \leq L \leq L_{\max }\right),\left(P_{\min } \leq P \leq P_{\max }\right)$

The ranges of design parameters in optimization have been selected based on the developed RSM model ranges [18]. The GA mechanics is simple, involving copying binary strings and the binary strings' swapping [8]. The simplicity of operation and computational efficiency are the two main attractions of the GA approach [8]. The GA solves optimization problem iteratively based on the bio- 
logical evolution process in nature. The solution procedure of an optimization problem with GA begins with a set of parameter values or "chromosomes" (usually in the form of bit strings), which are randomly generated or selected [19] [20]. The entire set of these chromosomes comprise a "population" [21]. The chromosomes evolve during several iterations or "generations" [21] [22]. New generations called "offspring" are generated using the "crossover" and "mutation" technique [21]. "Crossover involves splitting two chromosomes and then combining one-half of each chromosome with the other pair" [21]. "Mutation involves flipping a single bit of a chromosome. The chromosomes are then "evaluated" using specific "fitness" criteria, and the best ones are kept while the others are discarded" [21]. "This process repeats until one chromosome has the best fitness and is taken as the best solution to the problem" [21].

MATLAB 2018a Toolbox for GA is used to develop the GA program (MathWorks Incorporation, 2018). The critical parameters in GA are such as "the size of the population" (80), "mutation", "number of generations", "crossover friction" (0.8). The developed RSM models for response prediction (Equation (2)) were used as fitness functions for the GA. The corresponding optimum design parameters are given in Table 3.

\subsection{Interaction between the Design Parameters}

The study of the response surface and contour graphs provides an approach for optimizing foldability efficiency and identifying the interaction between the design parameters [23]. "The contour plots are sagacious to measure various design parameters (independent), which affect the response with the marked feasible region and optimum point" [24]. The contour graph is given in Figure 5.

Figure 6 is a perturbation plot, which illustrates the effect of all the design parameters at the center point in the design space, and Figure 7 represents the predicted vs. actual plots. However, it is often seen in a practical situation that even though the main factors have little or little impact on the variability of a response, the interaction between those factors significantly impacts that [25].

\section{Results and Discussion}

Table 4 shows the DESIGN EXPERT software that suggests the design parameters obtained after single response optimizations and ten possible solutions.

In solution 1, i.e., the shown values of design parameters, it is $89.8 \%$ likely to

Table 3. The best design condition was found in GA for the experiment.

\begin{tabular}{cc}
\hline Parameters & Optimized Values \\
\hline Fold Angle, $F($ Degree $)$ & 179.559 \\
Length of the cycle, $L(\mathrm{~cm})$ & 74.1 \\
Height between seat and paddle, $P(\mathrm{~m})$ & 0.59 \\
The time required to fold the product $(\mathrm{sec})$ & 2.39 \\
(GA prediction) & \\
\hline
\end{tabular}


Table 4. Values of design parameters for the optimization of response.

\begin{tabular}{ccccccc}
\hline Solution & $\begin{array}{c}\text { Factor 1: } \\
\boldsymbol{F}(\text { Degree })\end{array}$ & $\begin{array}{c}\text { Factor 2: } \\
\boldsymbol{L}(\mathrm{cm})\end{array}$ & $\begin{array}{c}\text { Factor 3: } \\
\boldsymbol{P}(\mathrm{m})\end{array}$ & $\begin{array}{c}\text { Response } \\
(\text { second) }\end{array}$ & Desirability & \\
\hline 1 & 180.000 & 74.112 & $\mathbf{0 . 6 1 3}$ & 2.415 & $\mathbf{0 . 8 9 8}$ & Selected \\
2 & 180.000 & 74.296 & 0.613 & 2.415 & 0.898 & \\
3 & 180.000 & 73.842 & 0.613 & 2.415 & 0.898 & \\
4 & 180.000 & 74.269 & 0.614 & 2.415 & 0.898 & \\
5 & 180.000 & 74.544 & 0.613 & 2.415 & 0.898 \\
6 & 179.998 & 74.505 & 0.614 & 2.415 & 0.898 \\
7 & 180.000 & 73.388 & 0.615 & 2.415 & 0.898 & \\
8 & 180.000 & 73.422 & 0.613 & 2.415 & 0.898 & \\
9 & 179.999 & 74.429 & 0.609 & 2.415 & 0.898 & \\
10 & 180.000 & 75.033 & 0.610 & 2.415 & 0.898 & \\
\hline
\end{tabular}

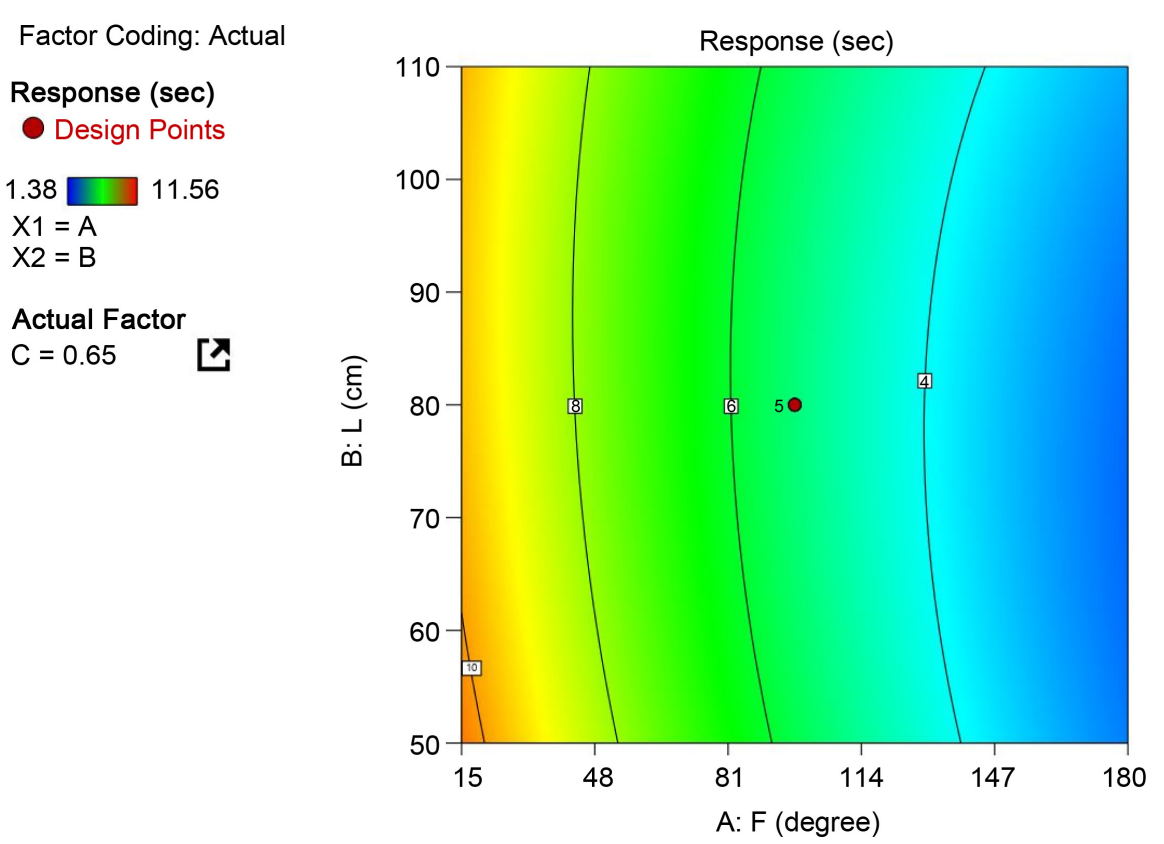

Figure 5. Contour Graph as a function of fold angle and length of the cycle.

get the Response $=2.415 \mathrm{sec}$. "Any other combination of the design parameters will either be statistically less reliable or give poor results of at least one response" [26]. However, these solutions could be used to achieve the possible values of the response. From Table 3 and Table 4, it is clear that RSM provides an optimum value of $2.415 \mathrm{sec}$, where GA predicts the optimum value is 2.39 sec.

The above design parameters will allow "minimum folding time", which will be achieved by combining the selected design parameters to develop its design and development phases. 
Factor Coding: Actual

Response (sec)

Actual Factor

$A=97.5$

$B=80$

$C=0.65$

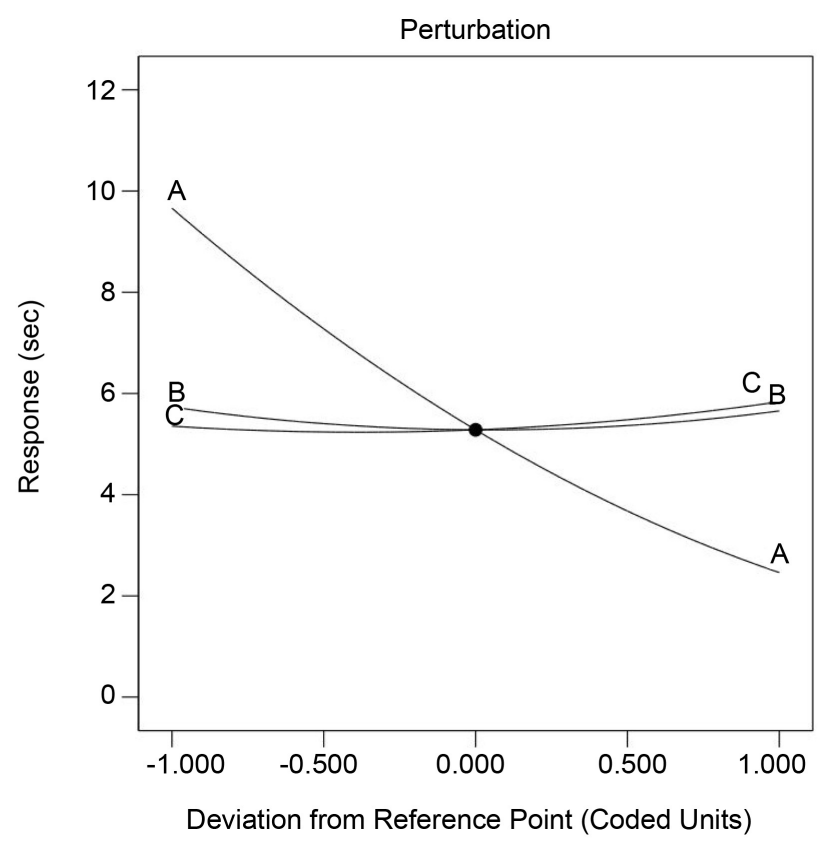

Figure 6. Perturbation graph for the response.

Response

Color points by value of Response:

$1.38 \square 11.56$

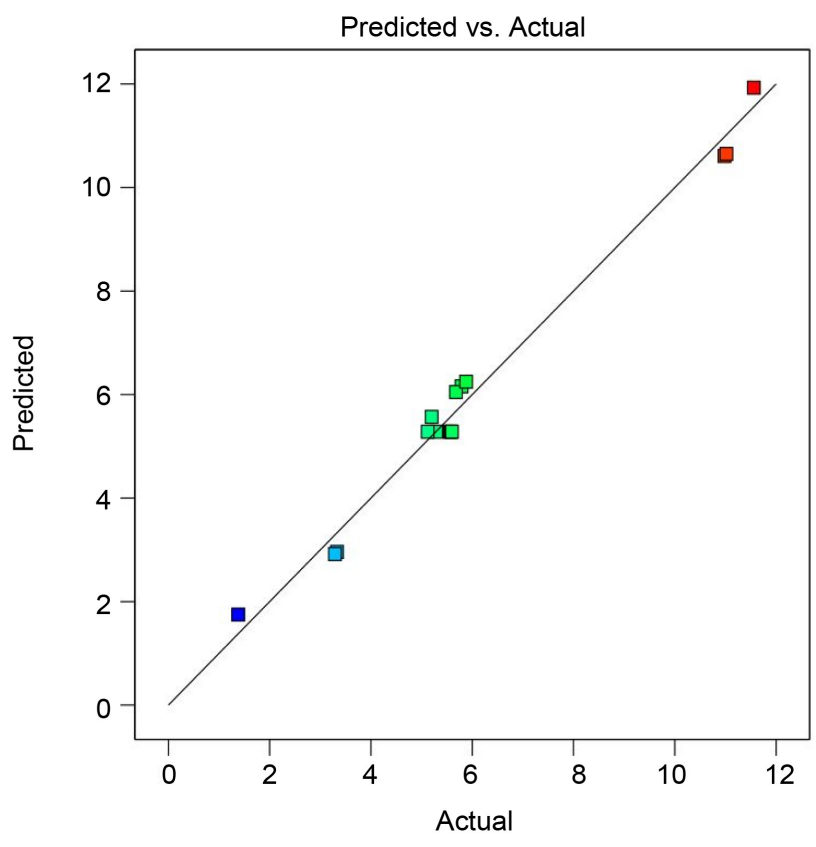

Figure 7. Predicted vs. Actual graph.

\section{Conclusions}

The interactions of the parameters are assessed on the grounds that quality attributes should ideally be added substance (i.e., no collaboration exists among the quality qualities) and monotonic (i.e., each factor's impact on robustness must be a predictable way, in any event, when the settings of variables are changed), however, it is regularly found in a pragmatic circumstance that despite the fact that the fundamental elements have close to nothing or little effect on 
the changeability of a reaction, the cooperation between those elements essentially impacts that. In this study, a foldable product is considered whose folding process is subjected to improvement using RSM and GA. The main objective is to determine the optimum time required to fold the cycle, predicting some future modifications of the folding mechanism. The following recommendations are for future works:

- Experimentation can be done using a more comprehensive set of design parameters.

- Other responses like stress analysis, materials density can be considered for model development.

- Finite Element Analysis (FEA) may be used to make the production process more reliable.

\section{Conflicts of Interest}

The authors declare no conflicts of interest regarding the publication of this paper.

\section{References}

[1] Wang, F.K., Yeh, C.T. and Chu, T.P. (2016) Using the Design for Six Sigma Approach with TRIZ for New Product Development. Computers \& Industrial Engineering, 98, 522-530. https://doi.org/10.1016/j.cie.2016.06.014

[2] Bartz-Beielstein, T., Lasarczyk, C.W.G. and Preuss, M. (2005) Sequential Parameter Optimization. 2005 IEEE Congress on Evolutionary Computation Proceedings, Vol. 1, 773-780.

[3] Roh, J., Hyeong, J. and Kim, S. (2018) Influence of Folding Mechanism of Bicycles on Their Usability. Applied Ergonomics, 69, 58-65.

https://doi.org/10.1016/j.apergo.2018.01.003

[4] Erfani, A., Muhammadi, M., Asgari Neshat, S., Shalchi, M.M. and Varaminian, F. (2015) Investigation of Aluminum Primary Batteries Based on Taguchi Method. Energy Technology \& Policy, 2, 19-27. https://doi.org/10.1080/23317000.2014.999292

[5] Bezerra, M.A., Santelli, R.E., Oliveira, E.P., Villar, L.S. and Escaleira, L.A. (2008) Response Surface Methodology (RSM) as a Tool for Optimization in Analytical Chemistry. Talanta, 76, 965-977. https://doi.org/10.1016/j.talanta.2008.05.019

[6] Alam, S., Patwari, A.U. and Lumpur, K. (2010) Surface Texture Investigation in High-Speed Flat End Milling of Ti-6Al-4V. Proceedings of the 2010 International Conference on Industrial Engineering and Operations Management, Dhaka, 9-10 January 2010, 1-6.

[7] Ozcelik, B. and Erzurumlu, T. (2006) Comparison of the Warpage Optimization in the Plastic Injection Molding Using ANOVA, Neural Network Model and Genetic Algorithm. Journal of Materials Processing Technology, 171, 437-445. https://doi.org/10.1016/j.jmatprotec.2005.04.120

[8] Kumar, S., Meenu and Satsangi, P.S. (2012) A Genetic Algorithmic Approach for Optimization of Surface Roughness Prediction Model in Turning Using UD-GFRP Composite. Indian Journal of Engineering and Materials Sciences, 19, 386-396.

[9] Mital, A. and Mehta, M. (1988) Surface Finish Prediction Models for Fine Turning. 
International Journal of Production Research, 26, 1861-1876. https://doi.org/10.1080/00207548808948001

[10] Abd, M.K.N. (2005) Performance Evaluation of Coated Carbide Tools When Turning Hardened Tool Steel. Universiti Teknologi Malaysia, Skudai.

[11] Alauddin, M. (1993) End Milling Machinability Studies for Steel, a Nickel-Base Alloy (Inconel 718) and a Metal Matrix Composite. Dublin City University, Dublin, $1-334$.

[12] Anayet, M., Patwari, U., Amin, A.K.M.N. and Arif, M.D. (2011) Optimization of Surface Roughness in End Milling of Medium Carbon Steel by Coupled Statistical Approach with Genetic Algorithm. 1st International Conference on Interdisciplinary Research and Development, Vol. 19, 41.1-41.5.

[13] Kulkarni, S. and Kulkarni, S. (2016) Process Development Part 2: Exploring the Dimensional Process via the DOE. In: Robust Process Development and Scientific Molding, Elsevier, Amsterdam, 225-267.

https://doi.org/10.3139/9781569905876.009

[14] Shivakumar, H., Patel, R. and Desai, B. (2008) Formulation Optimization of Propranolol Hydrochloride Microcapsules Employing Central Composite Design. Indian Journal of Pharmaceutical Sciences, 70, 408-413. https://doi.org/10.4103/0250-474X.43024

[15] Ai, M., Hickernell, F.J. and Lin, D.K.J. (2008) Optimal Fold-Over Plans for Regular s-Level Fractional Factorial Designs. Statistics \& Probability Letters, 78, 896-903. https://doi.org/10.1016/j.spl.2007.09.017

[16] Roosta, M., Ghaedi, M., Daneshfar, A., Sahraei, R. and Asghari, A. (2014) Optimization of the Ultrasonic Assisted Removal of Methylene Blue by Gold Nanoparticles Loaded on Activated Carbon Using Experimental Design Methodology. Ultrasonics Sonochemistry, 21, 242-252. https://doi.org/10.1016/j.ultsonch.2013.05.014

[17] Yunus, N.A., Gernaey, K.V., Woodley, J.M. and Gani, R. (2014) A Systematic Methodology for Design of Tailor-Made Blended Products. Computers \& Chemical Engineering, 66, 201-213. https://doi.org/10.1016/j.compchemeng.2013.12.011

[18] Jiang, R., Chen, X., Ge, R., Wang, W. and Song, G. (2018) Influence of TiB2 Particles on Machinability and Machining Parameter Optimization of TiB2/Al MMCs. Chinese Journal of Aeronautics, 31, 187-196. https://doi.org/10.1016/j.cja.2017.03.012

[19] Sood, P.K., Sehgal, R. and Dwivedi, D.K. (2011) Optimization of Turning Parameters for Surface Roughness in CNC Turning. I-Manager's Journal on Mechanical Engineering, 1, 26-30. https://doi.org/10.26634/jme.1.1.1214

[20] Ozcelik, B. and Erzurumlu, T. (2005) Determination of Effecting Dimensional Parameters on Warpage of Thin Shell Plastic Parts Using Integrated Response Surface Method and Genetic Algorithm. International Communications in Heat and Mass Transfer, 32, 1085-1094. https://doi.org/10.1016/j.icheatmasstransfer.2004.10.032

[21] Vishwakarma, C.B. and Prasad, R. (2009) MIMO System Reduction Using Modified Pole Clustering and Genetic Algorithm. Modelling and Simulation in Engineering, 2009, Article ID: 540895. https://doi.org/10.1155/2009/540895

[22] Kramer, O. (2017) Genetic Algorithms. In: Kramer, O., Ed., Genetic Algorithm Essentials, Studies in Computational Intelligence Vol. 679, Springer, Berlin, 11-19. https://doi.org/10.1007/978-3-319-52156-5 2

[23] Lenth, R.V. (2009) Response-Surface Methods in R, Using RSM. Journal of Statistical Software, 32, 1-17. https://doi.org/10.18637/jss.v032.i07 
[24] Mia, M., Al Bashir, M. and Dhar, N.R. (2016) Effects of Cutting Parameters and Machining Environments on Surface Roughness in Hard Turning Using Design of Experiment. AIP Conference Proceedings, 1754, Article ID: 060012. https://doi.org/10.1063/1.4958453

[25] Hahn, G.J. (1977) Some Things Engineers Should Know about Experimental Design. Journal of Quality Technology, 9, 13-20. https://doi.org/10.1080/00224065.1977.11980759

[26] Venkateswarlu, G., Davidson, M.J. and Sammaiah, P. (2014) Effect of Friction Stir Processing Process Parameters on the Mechanical Properties of AZ31B Mg Alloy. The Open Industrial \& Manufacturing Engineering Journal, 13, 1-5.

https://doi.org/10.12776/mie.v13i1-2.338 